\title{
Research on Brand Loyalty of Smart Phone Customer in Fast Iterative Context
}

\author{
Qiang Yang ${ }^{\mathrm{a}}$, Jiaojiao Lv \\ School of Management, Tianjin University of Technology, Tianjin300384,China \\ ayangqiang7201@163.com, ${ }^{\mathrm{b}}$ lvjiaojiao1027@163.com
}

Keywords: Rapid Iteration, Smartphone, Customer Perceived Value, Customer Satisfaction, Customer Loyalty.

\begin{abstract}
In the mobile Internet era, the innovation and development of intelligent terminal are improving with each passing day and the rapid iterative phenomenon of smart phones is not uncommon, but the enterprises easily lost the direction in the process of upgrading the product with continuous improvement but little success. In this case, companies should focus on the factors which affect consumer brand loyalty to maintain and continue to improve consumer brand loyalty. Based on Fernandre logic model, this paper builds the data model of customer loyalty and proposes the hypothesis. By issuing questionnaires, we collect and analyze the data, verify the hypothesis and conclude the conclusion. Finally, we put forward the advice about maintaining and improving the customer brand loyalty in the fast iteration situation.
\end{abstract}

\section{Introduction}

"2017 annual Chinese customer satisfaction survey results conference" held in Beijing on March 28, 2017, whose theme is "concern about customer satisfaction, build the Chinese brand" . The survey results show that: in terms of durable goods, consumers are more concerned about the technological innovation, green, energy security; in terms of fast-moving consumer goods(namely FMCG), consumers are more concerned about design, product innovation, packaging image. The smart phone industry is between the FMCG and durable goods more, which is supposed not only to focus on mobile phone technology innovation, but also to concern about the design, energy saving and environmental protection. However, in the Internet + era, the challenges facing the smart phone industry are far more than that, mainly including the following two aspects: on the one hand, the product replacement is frequent but the breakthrough innovation is lack and the phenomenon of product convergence is serious; On the other hand, the needs of consumers continue to upgrade, that they are no longer satisfied with the phone calls, sending text messages and other basic functions, but pay more attention to the added value of mobile phones. The existence of this contradiction may more or less adversely affect the maintenance of the old customers. Therefore, it is necessary for enterprises to pay attention to the factors that affect the customer brand loyalty and to focus on maintaining and continuously improving the customer's loyalty to the product brand, thus maintaining the continuous growth of enterprise income.

Based on the Fernandre logic model, this paper explores the relationship among customer perceived value, customer satisfaction and customer loyalty in the background of the rapid iteration of the smart phone in order to provide reference for the development of Smartphone industry in the future. 


\section{Literature Review and Hypothesis}

\section{The Fernando Logic Model}

In 1989, Dr. Fornell, working in the American National Quality Research Center at the University of Michigan Business School, presented a econometric model, also known as the Fernando logic model. This model mainly studies and determines the various factors of customer satisfaction index and is widely cited by many scholars in the 21st century.

This model includes variables such as customer perceived value, customer satisfaction, and customer loyalty. Customer perceived value refers to the consumer's perceived performance of the product or service and the balance of purchase expenses(Porter, 1985), which usually contains four dimensions, namely, functional value, experiential value, emotional value and cost value. The Functional value refers that the customers make the judgments of value about whether the product is able to meet their own needs after the purchase of products; experience value refers to the feelings of consumers in consumption; emotional value refers to the emotional satisfaction and inner feelings of consumer after the purchase of products; cost value refers to the cost payed by consumers in the entire shopping process, such as money or time. Customer satisfaction was introduced into the field of marketing by the famous scholar Cardozo (1965) in the 1960s, referring to the satisfaction of varying degrees when the customers purchase the products or service. Customer brand loyalty refers to the customary bias of consumers for the purchase of a branded product (Su Zhaohui, 2014). According to the model, we can see that customer perception of quality and customer expectation affect customer's perception of value and customer satisfaction. Customer's perception of value will positively affect customer satisfaction and customer satisfaction will positively affect customer loyalty.

\section{The Relationship between Customer Perceived Value and Customer Satisfaction}

There are two views on the relationship between customer perceived value and customer satisfaction: one is the value causal chain and the other is the satisfactory causal chain. The value causal chain is that the value of the customer perceived value determines the customer satisfaction, that is, the customer perceived value is the cause of customer satisfaction. The satisfaction causal chain is opposite, which means that satisfaction is the cause of the perceived value, that is, the level of customer perceived value is higher than customer satisfaction. Many scholars agree with the value chain of causality that satisfaction has a good predictive effect on the future behavior of consumers and perceived value is an important factor leading to consumer satisfaction. Based on this, the following assumptions are made:

H1:The functional value of customer perceived value has a positive effect on customer satisfaction;

H2:The experiential value of customer perceived value has a positive effect on customer satisfaction;

H3:The emotional value of customer perceived value has a positive effect on customer satisfaction;

H4:The cost value of customer perceived value has a positive effect on customer satisfaction.

\section{The Relationship between Customer Perceived Value and Customer Loyalty}

Bo Xiangping and Yin Hong (2005) in their study pointed out that customer perceived value is a key driver of brand loyalty. Sirohi et al. (1998) also pointed out that there is a positive correlation between customer perceived value and brand loyalty in a highly competitive environment. Fornell et al. (1996) argued that satisfaction is a variable between customer perceived value and customer loyalty and that customer perceived value is a factor in customer loyalty. Based on this, the following assumptions are made:

H5:The functional value of customer perceived value has a positive effect on customer loyalty;

H6:The experiential value of customer perceived value has a positive effect on customer loyalty;

H7:The emotional value of customer perceived value has a positive effect on customer loyalty;

H8:The cost value of customer perceived value has a positive effect on customer loyalty. 


\section{The Relationship between Customer Satisfaction and Customer Loyalty}

Jones and Sasser (1995) have found that the relationship between customer loyalty and customer satisfaction is influenced by industry competition. In low-competition industries, customer satisfaction has less impact on customer loyalty. But this is a false impression, because in the case of low competition, the customer's choice is limited. Even if not satisfied, they are often out of frustration to continue to use the product. In a highly competitive industry, fully satisfied customers are far more loyal than satisfied customer. In the case of full customer satisfaction, as long as the degree of customer satisfaction decreases slightly, the possibility of customer loyalty will be a sharp decline. This shows that to cultivate customer loyalty, companies must try to make customers completely satisfied. In the fast iteration of the mobile phone market, such a high degree of competition in the industry, only high customer satisfaction is likely to bring high customer loyalty. After all, the mobile phone industry is not a monopoly industry, consumers have many mobile phone brands to choose. Based on this, the following assumptions are made:

H9:Customer satisfaction has a positive impact on customer loyalty.

\section{Questionnaire Survey and Analysis of Customer Loyalty of Smartphone}

\section{Sample Analysis}

In this study, the questionnaire survey method IS used to investigate the local Smartphone users. A total of 180 questionnaires areissued and 168 questionnaires are collected. Fifty-three valid questionnaires are obtained after checking out the incomplete and incomplete questionnaires. The characteristics of the sample are as follows: male is 55 people, accounting for $35.9 \%$ and female is 98 people, accounting for 64.1\%.The number of people who are 18 years old and below is 3 , accounting for $2.0 \%$;the number of people who are $18-24$ years old is 86 , accounting for $56.2 \%$;the number of people who are $24-35$ years old is 42 , accounting for $27.5 \%$; the number of people who are 35 years old and above is 22, accounting for $14.4 \%$.There are 3 junior high school students, accounting for $2.0 \%$, there are 4 high school students, accounting for $2.6 \%$; there are 126 college students , accounting for $82.4 \%$, there are 20 graduates and above, accounting for $13.1 \%$.

\subsection{Reliability and Validity Test}

In this study, the scales are from the mature scale in the existing literature and are made appropriate adjustments in the pre-research before the formal research according to the test situation. Data are processed using SPSS software and Cronbach's coefficients is used to test the reliability of each scale. If Cronbach's a value is greater than 0.7 , it generally indicates that the reliability of the scale level is good. The results show that the $\alpha$ coefficient of functional value is 0.810 ; the acoefficient of empirical value is 0.707 ; the $\alpha$ coefficient of emotional value is 0.777 ; the $\alpha$ coefficient of cost value is 0.825 ; the coefficient of customer satisfaction is 0.746 ; the $\alpha$ coefficient of customer loyalty is 0.743 : that is, the variable scale reliability is good. In this study, KMO values and Bartlett spherical tests are performed using SPSS. The results show that the KMO value of functional values is 0.795 ; the KMO value of empirical value is 0.851 ; the KMO value of emotional value is 0.762 ; the $\mathrm{KMO}$ value of cost value is 0.797 ; the KMO value of customer satisfaction is 0.770 ; the KMO value of customer loyalty is 0.746. The statistics of Bartlett test are significant at the level of less than 0.001 , which indicates that the questionnaire has good discriminant validity.

\section{Regression Analysis}

Using SPSS statistical software to do the regression analysis among the customer perceived value, customer satisfaction and customer loyalty, the results are shown in Table 1. 
Table 1 the Regression Analysis among Customer Perceived Value, Customer Satisfaction and Customer Loyalty

\begin{tabular}{|c|c|c|c|c|c|c|c|c|c|c|c|}
\hline \multirow{2}{*}{ Variable } & \multicolumn{4}{|c|}{ Customer Satisfaction } & \multicolumn{7}{c|}{ Customer Loyalty } \\
\cline { 2 - 14 } & M1 & M2 & M3 & M4 & M5 & M6 & M6 & M7 & M8 & M9 & M10 \\
\hline Gender & -0.02 & -0.0 & 0.03 & 0.1 & 0.10 & 0.0 & -0.0 & 0.1 & -0.0 & 0.19 & -0.07 \\
\hline Age & -0.18 & -0.0 & -0.02 & 0.0 & 0.05 & -0. & -0.0 & -0.0 & 0.1 & -0.0 & -0.04 \\
\hline Education & -0.14 & -0.0 & -0.10 & 0.0 & 0.01 & -0. & -0.0 & 0.1 & 0.0 & 0.10 & -0.10 \\
\hline Functional & & 0.3 & & & & & 0.07 & & & & \\
\hline Empirical & & & 0.32 & & & & & 0.1 & & & \\
\hline Emotional & & & & 0.2 & & & & & -0.0 & & \\
\hline Cost Value & & & & & 0.38 & & & & & 0.30 & \\
\hline CustomerS & & & & & & & & & & & 0.36 \\
\hline
\end{tabular}

Note: * means $\mathrm{p}<0.05, * *$ means $\mathrm{p}<0.01, * * *$ means $\mathrm{p}<0.001$.

After adding the control variables, the regression analysis of customer perceived value and customer satisfaction is as follows: the functional value has a positive effect on customer satisfaction and the effect is significant $(\beta=0.393, p<0.05)$, which means that $\mathrm{H} 1$ is established. The empirical value has a positive effect on customer satisfaction and the effect is significant $(\beta=$ $0.324, \mathrm{p}<0.001$ ), which means that $\mathrm{H} 2$ is established. The emotional value has a positive effect on customer satisfaction and the effect is significant $(\beta=0.273, p<0.05)$, which means that $\mathrm{H} 3$ is established. The cost value has a positive effect on customer satisfaction and the effect is $\operatorname{significant}(\beta=0.389, \mathrm{p}<0.001)$, which means that $\mathrm{H} 4$ is established.

After adding the control variables, the regression analysis of customer perceived value and customer loyalty is as follows: the functional value has not a positive effect on customer loyalty $(\beta=$ 0.073, $\mathrm{p}>0.05$ ), which means that $\mathrm{H} 5$ is not established. The empirical value has a positive effect on customer loyalty and the effect is significant $(\beta=0.157, \mathrm{p}<0.05)$, which means that H6 is established. The emotional value has not a positive effect on customer loyalty $(\beta=-0.001, p>0.05)$, which means that $\mathrm{H} 7$ is not established. The cost value has a positive effect on customer loyalty and the effect is significant $(\beta==0.309, \mathrm{p}<0.001)$, which means that $\mathrm{H} 8$ is established.

After adding the control variables, the regression analysis of customer satisfaction and customer loyalty is as follows: the customer satisfaction has a positive effect on customer loyalty and the effect is significant $(\beta=0.363, p<0.001)$, which means that H9 is established.

\section{Summary}

Through the above analysis, it is not difficult to find that the functional value, the experiential value, the emotional value and the cost value of the customer perceived value have positive influence on the customer's satisfaction; the experiential value and the cost value of the customer perceived value has a positive impact on the customer loyalty; customer satisfaction has a positive impact on customer loyalty; but the functional value and emotional value of the customer perceived value has not significant impact on customer loyalty. That is, the remaining assumptions are true except $\mathrm{H} 5$ and $\mathrm{H} 7$. We make the following analysis about the reason why $\mathrm{H} 5$ and $\mathrm{H} 7$ are not established.

There are mainly two aspects explaining why the impact of functional value on customer loyalty is not significant. On the one hand, electronic products are faced with frequent replacement which is lack of innovation. And in the current market, the functional convergence of smart phone is serious, which is not enough to retain the old customers. On the other hand, the smart phone iteration updating, the costs increase simultaneously when the function is improved which means the corresponding sales price will increase and may be the counterproductive effectin the sales marketing process. However, the functional value has a positive impact on customer satisfaction, indicating that the functional value is not necessary but also is essential in the current rapid iterative situation. If the function does not meet the needs of consumers, it is easy to lead to the decline in 
customer satisfaction and customer loyalty will get a negative impact. The effect of emotional value on customer loyalty is not significant, mainly because the increase in emotional value occurs after the consumption of the stage, which will be affected by the functional experience and words of mouth and many other factors.

In summary, the suggestions about how to maintain and enhance the customer brand loyalty of smart phone are as follows: Firstly, the enterprise ought to pay attention to the promotion of mobile phone functions and develop innovative products. In the premise of ensuring the quality of mobile phones, the phone features are supposed to be constantly improved, which requires enterprises focus on innovation, such as designate the appropriate system to encourage and reward innovative activities to improve innovation initiative. Secondly, the enterprise ought to focus on improving the quality of service. Sales are not just products, more importantly, services. Good customer service can increase customer loyalty and win a good reputation. In addition, efforts should be made to enrich the brand culture soft power and establish a brand image. Brand culture is not only to focus on their own brand, but also to observe the concerns of consumers, because the brand culture can play its value when it gets the recognition of the consumers. Brand culture should have its own brand characteristics and personality, which is easy to identify in the market. That is to say, the enterprises need to learn to avoid weaknesses and shape the brand character. Finally, the enterprises should pay attention to make the rational prices of mobile phone. In the premise of profit, it is supposed to be finish the maximum to meet customer expectations. And it is important to maintain the stability of the price and avoid ups and downs. Raising prices will allow consumers to consider that the brand does not attach importance to consumers and regular price discounts will allow consumers to consider that the value of the product is not the original price shown on the brand which will cause a bad impression.

\section{References}

[1]Porter M.E. Competitive Advantage[M]. New York: Free Press.1985:95-102.

[2]Cardozo R M. An Experimental Study of Consumer Effort, Expectation and Satisfaction[J].Journal of Marketing Research, 1965:244-249.

[3]Su Zhaohui. Customer Relationship Management: The Establishment and Maintenance of Customer Relationship Management(Third Edition)[M]. Beijing: Tsinghua University Press, 2014:229.

[4]Bo Xiangping, Yin Hong. Analysis on Customer Loyalty Management of Service Enterprises Based on Customer Value[J].Economy and Management,2005:99-102.

[5]Sirohi N.,Melaughlin E.W.,Wittink D.R. A Modal of Customer Perception and Store Loyalty Intention for a Supermarket Retailer[J]Journal of Retailing,1998:227.

[6]Fornell C.,Johnson M.D., Anderson E.W., Cha J., Bryant B.E. The American Customer Satisfaction Index:Nature, Purpose and Findings[J]. Journal of Marketing,1996(60):7-18.

[7]JonesT.O.,SasserW.E. Why Satisfied Customers Defect[J].Harvard Business Review, 1995:11-12. 